\title{
NDVI e SAVI como ferramentas de monitoramento das modificações no uso e ocupação do solo no sudoeste paraense
}

NDVI and SAVI as tools for monitoring changes in land use and occupation in southwestern Pará NDVI y SAVI como herramientas para monitorear cambios en el uso y ocupación del suelo en el suroeste de Pará

Hellem Cristina Teixeira Rodrigues

ORCID: https://orcid.org/0000-0003-2671-8742 Secretaria de Estado de Meio Ambiente e Sustentabilidade, Brasil E-mail: hellem.cristinat@gmail.com

Rayssa Soares Da Silva

ORCID: https://orcid.org/0000-0003-4626-6384 Universidade Federal Rural da Amazônia, Brasil E-mail: rayssacereja@gmail.com

Francimary da Silva Carneiro ORCID: https://orcid.org/0000-0002-1693-8779 Secretaria de Estado de Meio Ambiente e Sustentabilidade, Brasil

E-mail: francimarycarneiro@gmail.com

Charles Benedito Gemaque Souza

ORCID: https://orcid.org/0000-0002-5966-9556 Secretaria de Estado de Meio Ambiente e Sustentabilidade, Brasil

E-mail: gemaque.charles@gmail.com.br

Tamires Borges de Oliveira ORCID: https://orcid.org/0000-0003-4661-7172 Secretaria de Estado de Meio Ambiente e Sustentabilidade, Brasil

E-mail: tamires.rasr@gmail.com

Ana Paula Magno do Amaral

ORCID: https://orcid.org/0000-0002-1749-791X Secretaria de Estado de Meio Ambiente e Sustentabilidade, Brasil

E-mail: magno_ana@yahoo.com.br

Ana Marcela Alves dos Santos

ORCID: https://orcid.org/0000-0002-9498-8587 Secretaria de Estado de Meio Ambiente e Sustentabilidade, Brasil

E-mail: anamarcela-santos@hotmail.com

Klewton Adriano Oliveira Pinheiro

ORCID: https://orcid.org/0000-0003-2696-4249

Instituto Federal do Pará, Brasil

E-mail: klewton.pinheiro@gmail.com

Mayra Piloni Maestri

ORCID: https://orcid.org/0000-0002-8936-952X

Secretaria de Estado de Meio Ambiente e Sustentabilidade, Brasil

E-mail: mayrapmaestri@hotmail.com

\begin{abstract}
Resumo
Sensoriamento Remoto é um uma tecnologia que permite aquisição de informações sobre áreas ou objetos sem manter contato físico. Esse trabalho objetivou utilizar imagens de satélites passivos, por meio dos índices de cobertura vegetal, como o Índice de Vegetação por Diferença Normalizada (NVDI) e Índice de Vegetação Ajustado para o Solo (SAVI), nos anos de 2008 e 2018, para identificar as modificações sofridas em 10 anos da comunidade Comunidade Linha Gaúcha localizada no município de Novo progresso no estado do Pará. Para este trabalho, foram utilizados dados provenientes do IBAMA, como a localização espacial da Comunidade e imagens da plataforma United States Geological Survey (USGS), para os anos de 2008(Landsat 5 - TM) e 2018 (Landsat 8 - OLI). Por meio do método de NDVI e SAVI foi possível analisar a expansão urbana em torno da comunidade num raio de $50 \mathrm{~km}$, assim como observar a intensa modificação no uso e ocupação do solo, estando este fato intimamente ligado à presença da rodovia Transamazônica, importante agente de crescimento na Amazônia.
\end{abstract}

Palavras-chave: Análise multitemporal; Geoprocessamento; Amazônia brasileira. 


\begin{abstract}
Remote Sensing is a technology that allows the acquisition of information about areas or objects without maintaining physical contact. This work aimed to use passive satellite images, through vegetation cover indices, such as the Normalized Difference Vegetation Index (NVDI) and Adjusted Soil Vegetation Index (SAVI), in the years 2008 and 2018, to identify the changes undergone in 10 years of the Comunidade Linha Gaúcha community located in the municipality of Novo Progresso in the state of Pará. For this work, data from IBAMA were used, such as the spatial location of the Community and images from the United States Geological Survey (USGS) platform. for the years 2008(Landsat 5 - TM) and 2018 (Landsat 8 - OLI). Through the NDVI and SAVI method, it was possible to analyze the urban expansion around the community within a radius of $50 \mathrm{~km}$, as well as observe the intense change in land use and occupation, this fact being closely linked to the presence of the Transamazon Highway, an important agent of growth in the Amazon.
\end{abstract}

Keywords: Multitemporal analysis; Geoprocessing; Brazilian Amazon.

\title{
Resumen
}

La Teledetección es una tecnología que permite la adquisición de información sobre áreas u objetos sin mantener contacto físico. Este trabajo tuvo como objetivo utilizar imágenes satelitales pasivas, a través de índices de cobertura vegetal, como el Índice de Vegetación de Diferencia Normalizada (NVDI) y el Índice de Vegetación de Suelo Ajustado (SAVI), en los años 2008 y 2018, para identificar los cambios experimentados en 10 años en el Comunidad Lina Gaúcha comunidad ubicada en el municipio de Novo Progreso en el estado de Pará. Para este trabajo se utilizaron datos del IBAMA, como la ubicación espacial de la Comunidad e imágenes de la plataforma del Servicio Geológico de los Estados Unidos (USGS). años 2008 (Landsat 5 - TM) y 2018 (Landsat 8 - OLI). A través del método NDVI y SAVI, fue posible analizar la expansión urbana alrededor de la comunidad en un radio de $50 \mathrm{~km}$, así como observar el intenso cambio de uso y ocupación del suelo, hecho que está íntimamente ligado a la presencia de la Carretera Transamazónica, un importante agente de crecimiento en la Amazonía.

Palabras clave: Análisis multitemporal; Geoprocesamiento; Amazonia Brasileña.

\section{Introdução}

Com o passar do tempo a tecnologia vem se reinventando e implementando novos usos aos sistemas existentes. A utilização de produtos e técnicas de sensoriamento remoto nas analises ambientais tem se tornado uma prática cada vez mais frequente entre as diversas áreas do conhecimento. Para analise do uso e cobertura do solo, essas técnicas contribuem para rapidez do processo e consequentemente a economia financeira da analise (Rosendo, 2005).

Como a natureza esta em constante evolução, seja por origem natural ou antrópica, se faz necessário compreender e analisar os fenômenos que contribuem para esta modificação. A observação da Terra por meio de satélites é a maneira mais efetiva e econômica de coletar os dados necessários para monitorar e modelar estes fenômenos, especialmente em países de grande extensão territorial, como o Brasil (Sausen, 2019).

Sensoriamento Remoto é um uma tecnologia que permite aquisição de informações sobre áreas ou objetos sem manter contato físico com eles. Por não haver contato físico, a forma de transmissão dos dados (do objeto para o sensor) só pode ser realizada pela Radiação Eletromagnética, por ser esta a única forma de energia capaz de se propagar pelo vácuo (MASPLAM, 2014). Por meio de software de processamento de imagens, pode-se gerar diversos produtos, para as mais variadas áreas.

O marco inicial do sensoriamento remoto é cientificamente ligado ao desenvolvimento da fotografia e à pesquisa espacial. As fotografias aéreas foram o primeiro produto de sensoriamento remoto a ser utilizado (Introdução, 2011). Hoje, tem-se diversas opções para obter imagens aéreas, seja proveniente de satélites orbitando a terra ou de capitação por aeronaves, tripuláveis ou não, como é o caso dos drones.

Um dos conceitos mais utilizados para o Sensoriamento Remoto (SR) é de Novo (1989), o SR pode ser definido como sendo a utilização conjunta de modernos sensores (câmeras), equipamentos para processamento de dados (software), equipamentos de transmissão de dados, aeronaves (fotografias aéreas), que têm por objetivo o estudo das interações no ambiente terrestre, entre a radiação eletromagnética e as substâncias componentes do planeta Terra em suas diversas manifestações, sem que haja o contato físico direto. 
Em linguagem mais direta tem-se o conceito de Florenzano (2007), Sensoriamento remoto é a tecnologia que permite obter imagens e outros tipos de dados da superfície terrestre, através da captação e do registro da energia refletida ou emitida pela superfície. O termo sensoriamento refere-se à obtenção dos dados, e remoto, que significa distante, é utilizado porque a obtenção é feita a distância (Figura 1). Agilizando a coleta de dados e possibilitando a economia nos recursos financeiros.

Figura 1: Ilustração princípio de funcionamento do SR.

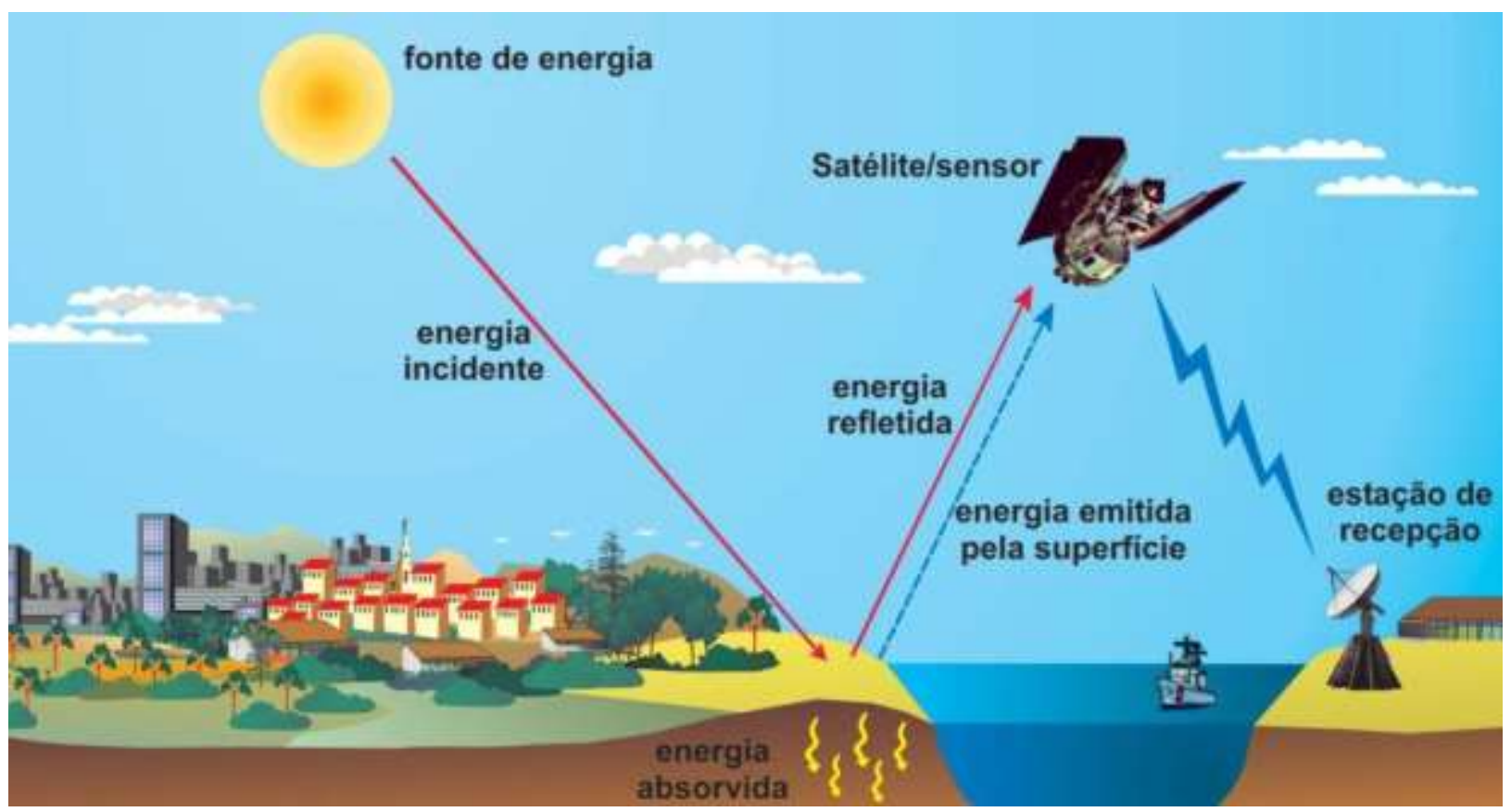

Fonte: Florenzano (2007).

O SR representa o avanço tecnológico nos mapeamentos, assim como apresenta singularidades que estão diretamente ligadas ao tipo de sensor que está sendo utilizado. Alguns parâmetros primordiais foram estabelecido para os sensores, tendo destaque a resolução espacial do mesmo, que pode prever se o sensor terá capacidade de atender as exigências previamente estabelecidas ao mapeamento. Com isso, quanto mais perto o sensor estiver do objeto, mais será a resolução espacial, disponibilizando imagens com maior quantidade de detalhes.

Os sistemas sensores são classificados em dois grupos, sendo ativos e passivos. Os sensores classificados com passivos não possuem uma fonte própria de energia eletromagnética, como por exemplo, os sensores do satélite Landsat 5 e Landsat 8 utilizados no trabalho, os radiômetros e espectroradiômetros (Moraes, 2002).

Os sensores ativos tem uma fonte própria de energia eletromagnética. Assim podem emitir energia eletromagnética para os objetos terrestres a serem imageados e detectam parte desta energia que é refletida por estes na direção destes sensores, um exemplo esse tipo de sensor é o radar e um mais utilizado é uma câmera fotográfica com flash.

De acordo com Novo (1989), cada sensor é caracterizado pela sua resolução, que significa uma medida da habilidade que o sensor possui de distinguir resposta espectralmente.

Os sistemas de varredura instalados em satélites podem ser caracterizados em termos de sua resolução espectral, que é uma medida da largura das faixas espectrais nas quais o sensor opera:

- Resolução radiométrica: Relacionada com a sensibilidade do sensor em distinguir entre dois níveis de intensidade do sinal de retorno.

- Resolução temporal: Relativa ao intervalo de tempo entre a aquisição de duas imagens de uma mesma área. 
Os sensores são mantidos no nível orbital (Figura 2), conhecido como satélites artificiais, assim permitindo a repetitividade das informações, assim um melhor monitoramento dos recursos naturais para grandes áreas da superfície terrestre (Moraes, 2002).

Figura 2: Coleta de Dados.

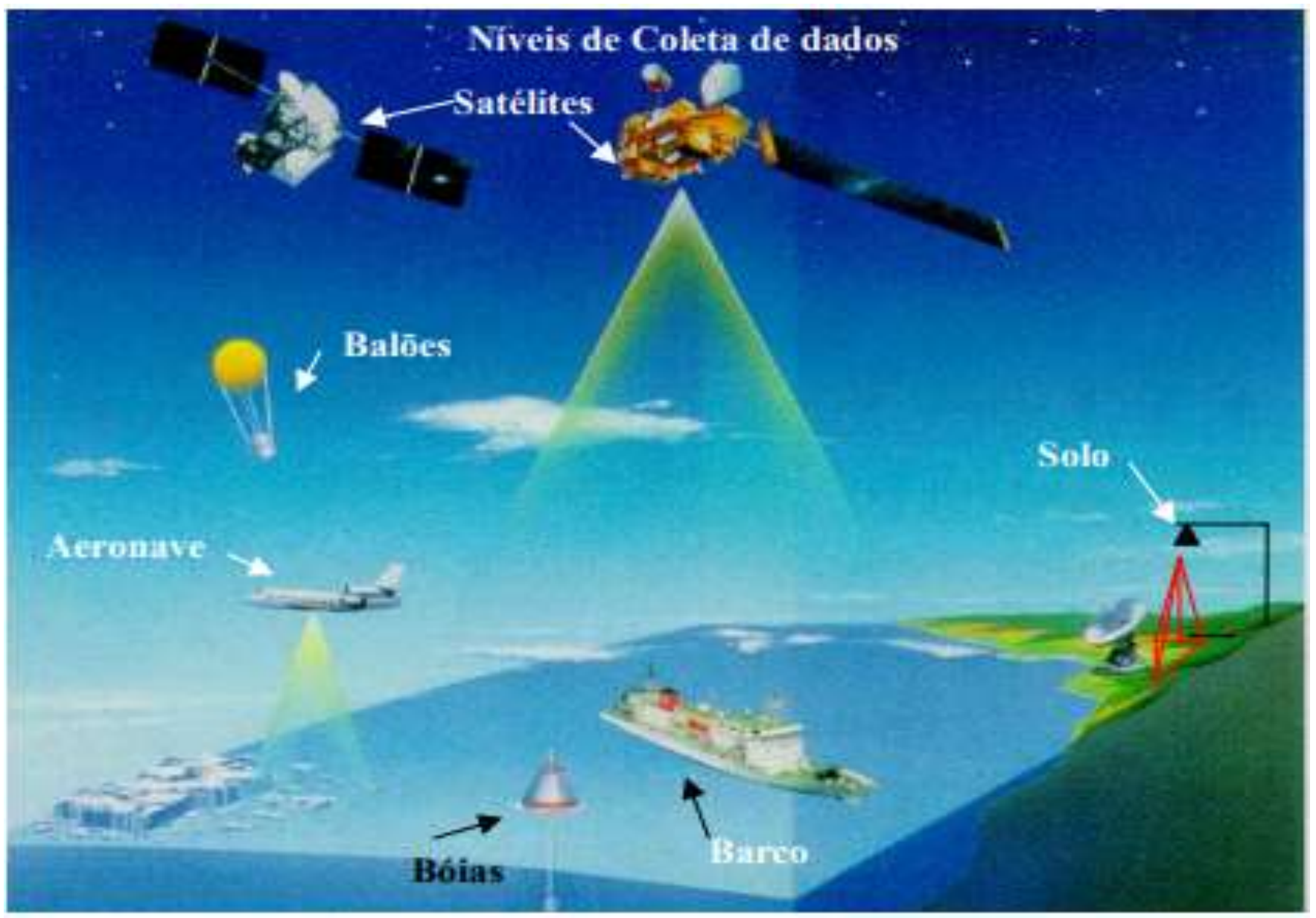

Fonte: Moreira (2001).

Devido às mudanças ambientais o uso do NDVI (Normalized Difference Vegetation Index) em estudos ambientais a relação existente entre esse método e da vegetação é bem estabelecida devido à ligação entre o índice e a fração de radiação ativa fotossinteticamente absorvida e interceptação (Pettorelli, 2005).

A partir de então diversos trabalhos foram desenvolvidos nessa perspectiva. Accioly et al (2002) discutem o papel do sensoriamento remoto na avaliação e no monitoramento dos processos de desertificação, Teotia et al (2003) utilizam o NDVI para classificação da cobertura vegetal como forma de subsídio para definir a capacidade de uso da terra.

A partir da formulação abaixo de acordo com Jensen (1996):

$$
N D V I=(N I R-R) /(N I R+R)
$$

Onde:

$\mathrm{NIR}=$ É reflectância no comprimento de onda correspondente ao Infravermelho próximo.

$\mathrm{R}=$ É a reflectância no comprimento de onda correspondente ao Vermelho.

Assim a vegetação fica exposta por uma intensa absorção devido a clorofila presente na região do vermelho e infravermelho próximo devido as estruturas das células das folhas (Melo, Sales \& Oliveira,2011). 
De acordo com Boratto e Gomide (2013) SAVI ressalta os efeitos do solo exposto nas imagens analisadas, contribuindo para o NDVI quando a superfície não está completamente tomada por vegetação.

O índice de vegetação ajustado ao solo tenta minimizar erros da reflectância do solo ao considerar a incorporação de um fator de ajuste dependente da densidade de vegetação como Gilabert (2002) afirma.

Formulação do SAVI:

$$
S A V I=\frac{\left(1+l_{s}\right)\left(p_{4}-p_{3}\right)}{\left(l_{s}+p_{4}+p_{3}\right)}
$$

Onde:

$L_{s}=$ Uma constante denominada de fator de ajuste do índice (SAVI). Conforme Huete (1988) 0.25 para vegetação densa e 0.5 para intermediaria, 1 para baixa vegetação.

$$
\begin{aligned}
& p_{a}=\text { vermelho } \\
& p_{4}=\text { NIR }
\end{aligned}
$$

Devido a todos esses fatores esse trabalho teve o intuito de utilizar imagens de satélites passivos, por meio dos índices de cobertura vegetal, Índice de Vegetação por Diferença Normalizada (NVDI) e Índice de Vegetação Ajustado para o Solo (SAVI), para os anos de 2008 e 2018, para no final, realizar a diferença entre os anos e identificar as modificações sofridas em 10 anos da comunidade estudada.

\section{Metodologia}

Foram utilizados dados provenientes do IBAMA, como a localização espacial da Comunidade Linha Gaúcha e imagens da plataforma United States Geological Survey (USGS), para os anos de 2008(Landsat 5 - TM) e 2018 (Landsat 8 -

\begin{tabular}{|c|c|c|c|c|c|c|}
\hline Sensor & Bandas Espectrais & $\begin{array}{l}\text { Resolução } \\
\text { Espectral } \\
\end{array}$ & $\begin{array}{l}\text { Resolução } \\
\text { Espacial }\end{array}$ & $\begin{array}{l}\text { Resolução } \\
\text { Temporal }\end{array}$ & $\begin{array}{l}\text { Área } \\
\text { Imageada }\end{array}$ & $\begin{array}{l}\text { Res. } \\
\text { Radiométrica }\end{array}$ \\
\hline TM (Thematic & B1 - Azul & $0.45-0.52 \mu \mathrm{m}$ & $30 \mathrm{~m}$ & 16 dias & $185 \mathrm{~km}$ & 8 bits \\
\hline \multirow[t]{6}{*}{ Mapper) } & B2 - Verde & $0.52-0.60 \mu \mathrm{m}$ & & & & \\
\hline & B3 - Vermelho & $0.63-069 \mu \mathrm{m}$ & & & & \\
\hline & B4 - Infravermelho Próximo & $0.76-0.90 \mu \mathrm{m}$ & & & & \\
\hline & B5 - Infravermelho Médio & $1.55-1.75 \mu \mathrm{m}$ & & & & \\
\hline & B6 - Infravermelho Termal & $10.4-12.5 \mu \mathrm{m}$ & $120 \mathrm{~m}$ & & & \\
\hline & B7 - Infravermelho Médio & $2.08-2.35 \mu \mathrm{m}$ & $30 \mathrm{~m}$ & & & \\
\hline
\end{tabular}
OLI) da referida área de estudo, dados das imagens utilizadas disponíveis na Tabela 1 e 2.

Tabela 1: Características técnicas Landsat 5 - 227063_20080623_20161030_01_T1.

Fonte: EMBRAPA (2019).

Foram usadas as bandas B3 e B4 do satélite Landsat 5 da Tabela 1, para introduzir no processamento do índice de vegetação pelo método do SAVI e NDVI para o ano de 2008, considerando a comunidade Linha Gaúcha e o raio de 50 km da mesma, utilizando o Software Qgis, ArcGIS e ENVI para ajustar e processar os dados, respectivamente. 
Research, Society and Development, v. 11, n. 1, e47611122583, 2022

(CC BY 4.0) | ISSN 2525-3409 | DOI: http://dx.doi.org/10.33448/rsd-v11i1.22583

Tabela 2: Características técnicas Landsat 8 - OLI - 227063_20180721_20180731_01_T1.

\begin{tabular}{|c|c|c|c|c|c|c|}
\hline Sensor & Bandas Espectrais & $\begin{array}{l}\text { Resolução } \\
\text { Espectral }\end{array}$ & $\begin{array}{l}\text { Resoluçã } \\
\text { o } \\
\text { Espacial }\end{array}$ & $\begin{array}{l}\text { Resolução } \\
\text { Temporal }\end{array}$ & $\begin{array}{l}\text { Área } \\
\text { Imageada }\end{array}$ & $\begin{array}{l}\text { Resolução } \\
\text { Radiométrica }\end{array}$ \\
\hline $\begin{array}{l}\text { OLI (Operational } \\
\text { Land Imager) }\end{array}$ & $\begin{array}{l}\text { B1 - Costal } \\
\text { B2 - Azul } \\
\text { B3 - Verde } \\
\text { B4 - Vermelho } \\
\text { B5 - Infravermelho Próximo } \\
\text { B6 - Infravermelho Médio } \\
\text { B7 - Infravermelho Médio } \\
\text { B8 - Pancromático } \\
\text { B9 - Cirrus } \\
\text { B10-Infravermelho } \\
\text { Termal 1 } \\
\text { B11-Infravermelho } \\
\text { Termal } 2\end{array}$ & $\begin{array}{l}0.433-0.453 \mu \mathrm{m} \\
0.450-0.515 \mu \mathrm{m} \\
0.525-0.600 \mu \mathrm{m} \\
0.630-0.680 \mu \mathrm{m} \\
0.845-0.885 \mu \mathrm{m} \\
1.560-1.660 \mu \mathrm{m} \\
2.100-2.300 \mu \mathrm{m} \\
0.500-0.680 \mu \mathrm{m} \\
1.360-1.390 \mu \mathrm{m} \\
10.60- \\
11.19 \mu \mathrm{m} \\
11.50- \\
12.51 \mu \mathrm{m}\end{array}$ & $\begin{array}{l}15 \mathrm{~m} \\
30 \mathrm{~m}\end{array}$ & 16 dias & $185 \mathrm{~km}$ & 12 bits \\
\hline
\end{tabular}

Fonte: EMBRAPA (2019).

Foram usadas as bandas B4 e B5 do satélite Landsat 8 da Tabela 2, para introduzir no processamento do índice de vegetação pelo método do SAVI e NDVI para o ano de 2018, considerando a comunidade Linha Gaúcha e o raio de 50 km da mesma, utilizando o Software Qgis, ArcGIS e ENVI para ajustar e processar os dados, respectivamente.

Com isso, foi possível utilizar as fórmulas apresentadas neste relatório para o processamento e consequentemente a obtenção dos produtos de interesse, na qual, será apresentada no tópico de resultados e discussão.

\section{Resultados e Discussão}

\subsection{NDVI}

O primeiro produto, ou seja, dado elaborado foi o NDVI do ano de 2008 (Figura 3), de acordo Holben (1986) onde a cenas de vegetação o NDVI varia de 0.1 a 0.6, onde os valores mais altos estão associados à cobertura vegetal. No mapa do ano de 2008 é possível destacar áreas com tons de cinza mais claro a noroeste do mapa onde fica localizada a Reserva Flona Tapajós. Mesmo com a expansão urbana em torno da rodovia Transamazônica pode-se notar a preservação da área observada no mapa do ano de 2018 (Figura 4). 
Figura 3: Produto do NDVI da comunidade analisada para o ano de 2008.

NDVI da comunidade Linha Gaúcha - PA, ano 2008.
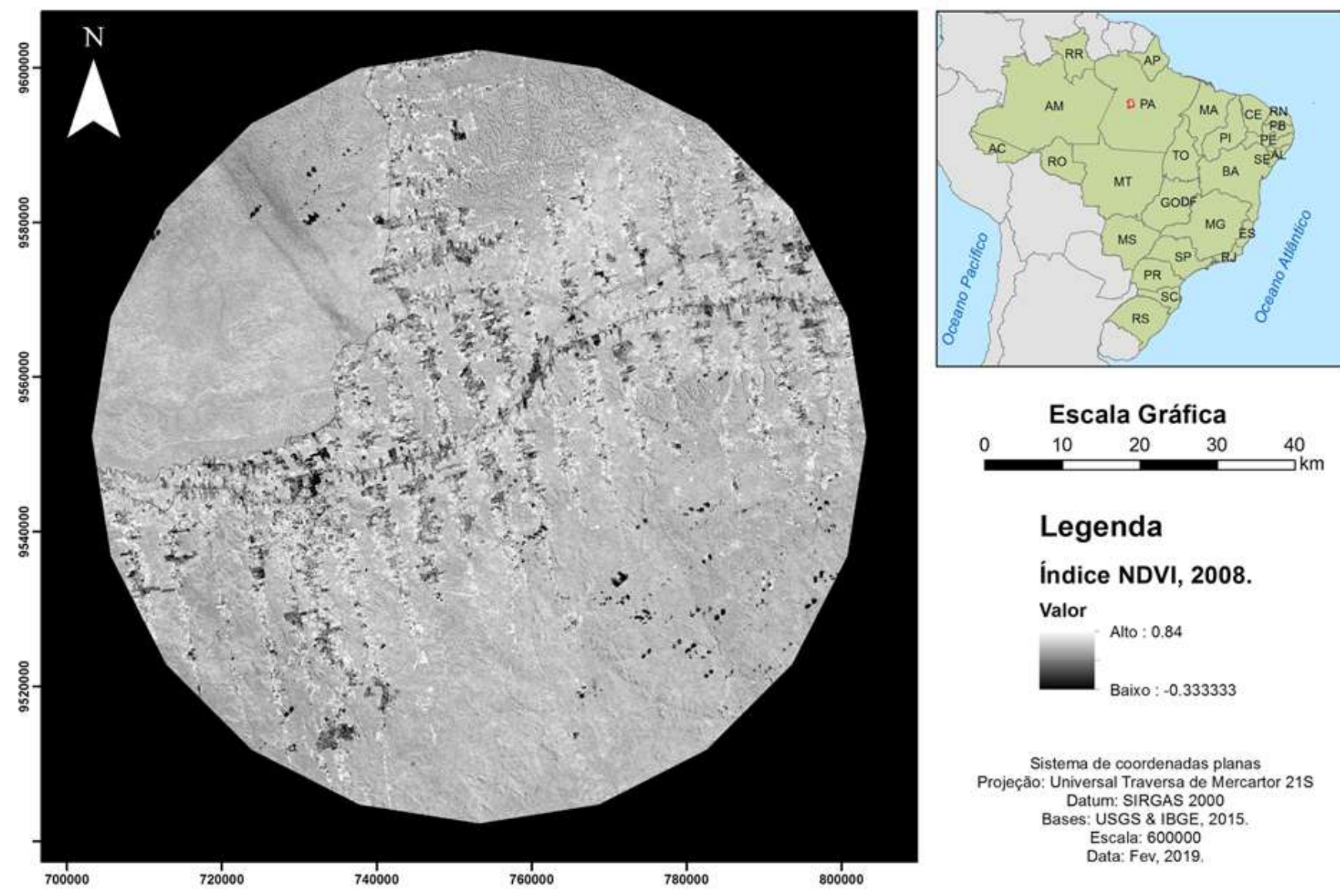

Legenda

Índice NDVI, 2008.

Valor

Alto : 0.84

Baixo: -0.333333

Sistema de coordenadas planas Projeçăo: Universal Traversa de Mercartor 21S Datum: SIRGAS 2000
Bases: USGS \& IBGE, 2015 Escala: 600000

Fonte: Autores.

Em torno da Transamazônica observa a expansão urbana e apresentação do solo exposto visto que em torno da rodovia pontos com tonalidades mais escuras é encontrado em ambos os anos. 
Figura 4: Produto do NDVI da comunidade analisada para o ano de 2018.

\section{NDVI da comunidade Linha Gaúcha - PA, ano 2018.}

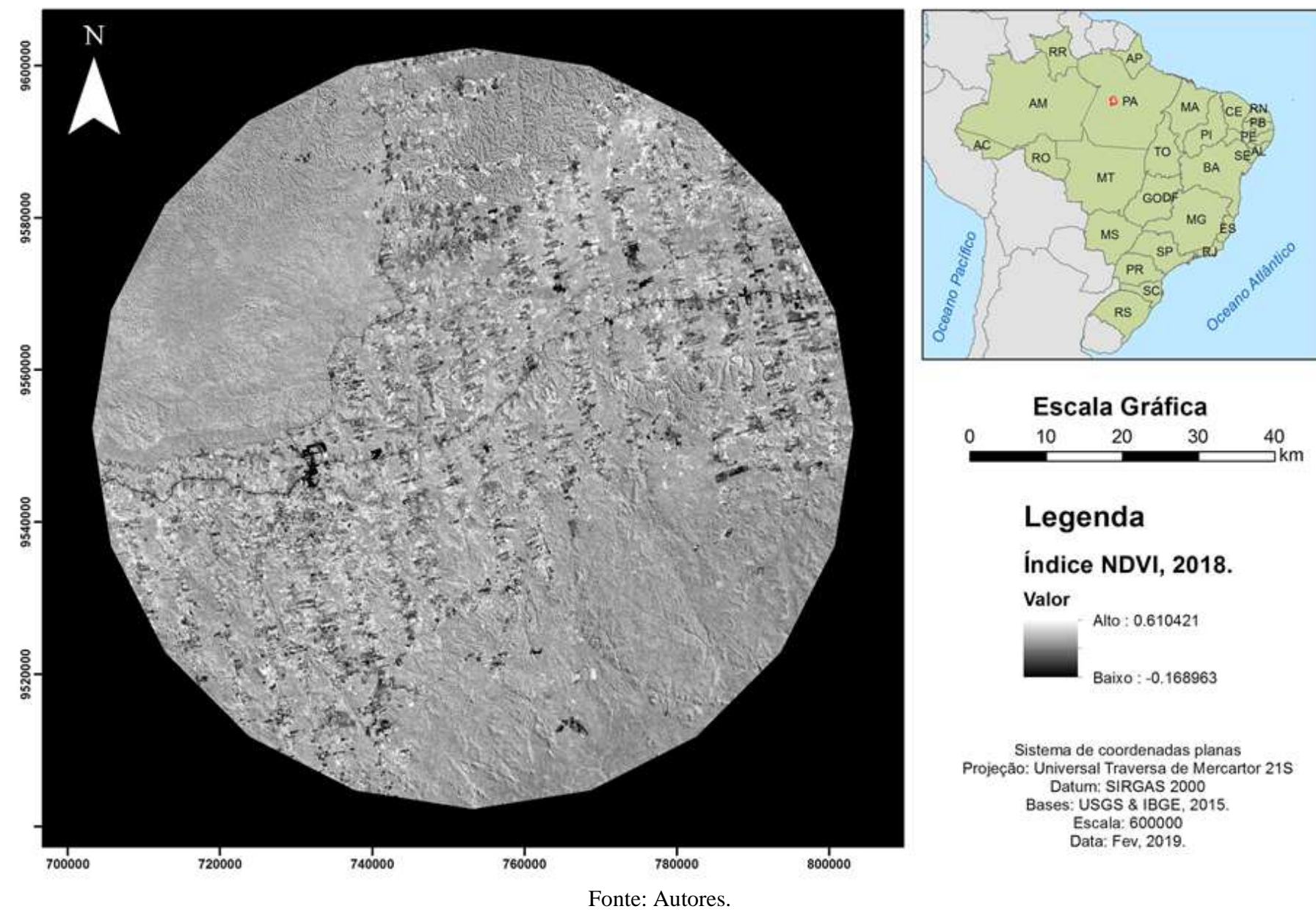

\subsection{SAVI}

O índice de Vegetação Ajustado ao Solo (SAVI) de acordo com Oliveira (2008) é um importante passo para estabelecer de um modelo global para classificar solo-vegetação nos dados de sensoriamento remoto. Pois através dos produtos desse método é notório o uso e ocupação do solo do mesmo, como se pode verificar nos produtos abaixo (Figura 5 e 6). O destaque para rodovia Transamazônica que contribuiu para a expansão urbana, característico da forma de espinha de peixe ou linear, criando linhas perpendiculares de crescimento. 
Figura 5: Produto do SAVI da comunidade analisada para o ano de 2008.

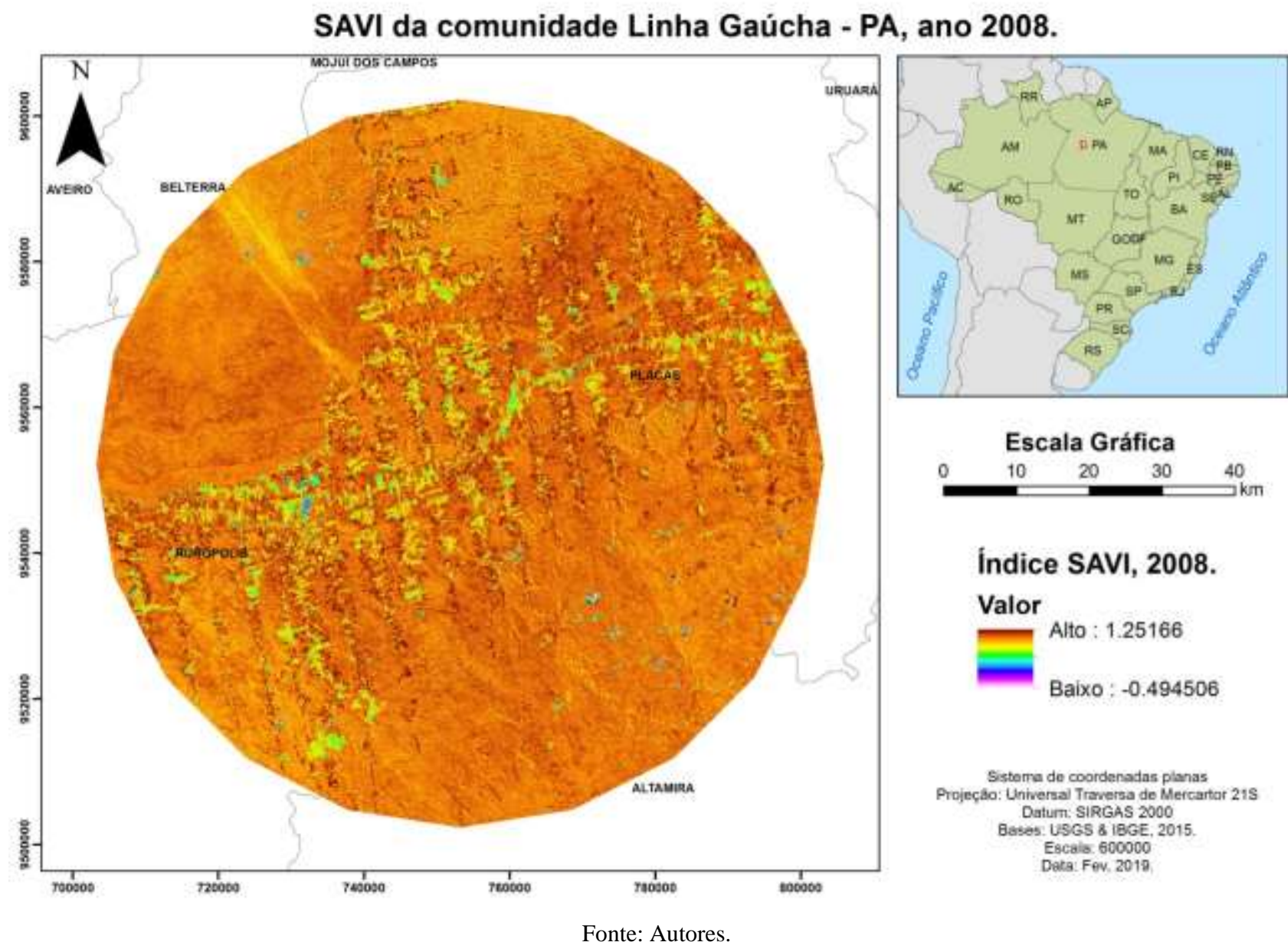

$\mathrm{Na}$ analise para o ano de 2018, também é possível observar o aumento da ocupação das linhas perpendiculares de crescimento. Em toda região do mapa, exceto na região noroeste do mapa, por conta da localização da Flona Tapajós (Figura 6). 
Figura 6: Produto do SAVI da comunidade analisada para o ano de 2018.

\section{SAVI da comunidade Linha Gaúcha - PA, ano 2018.}

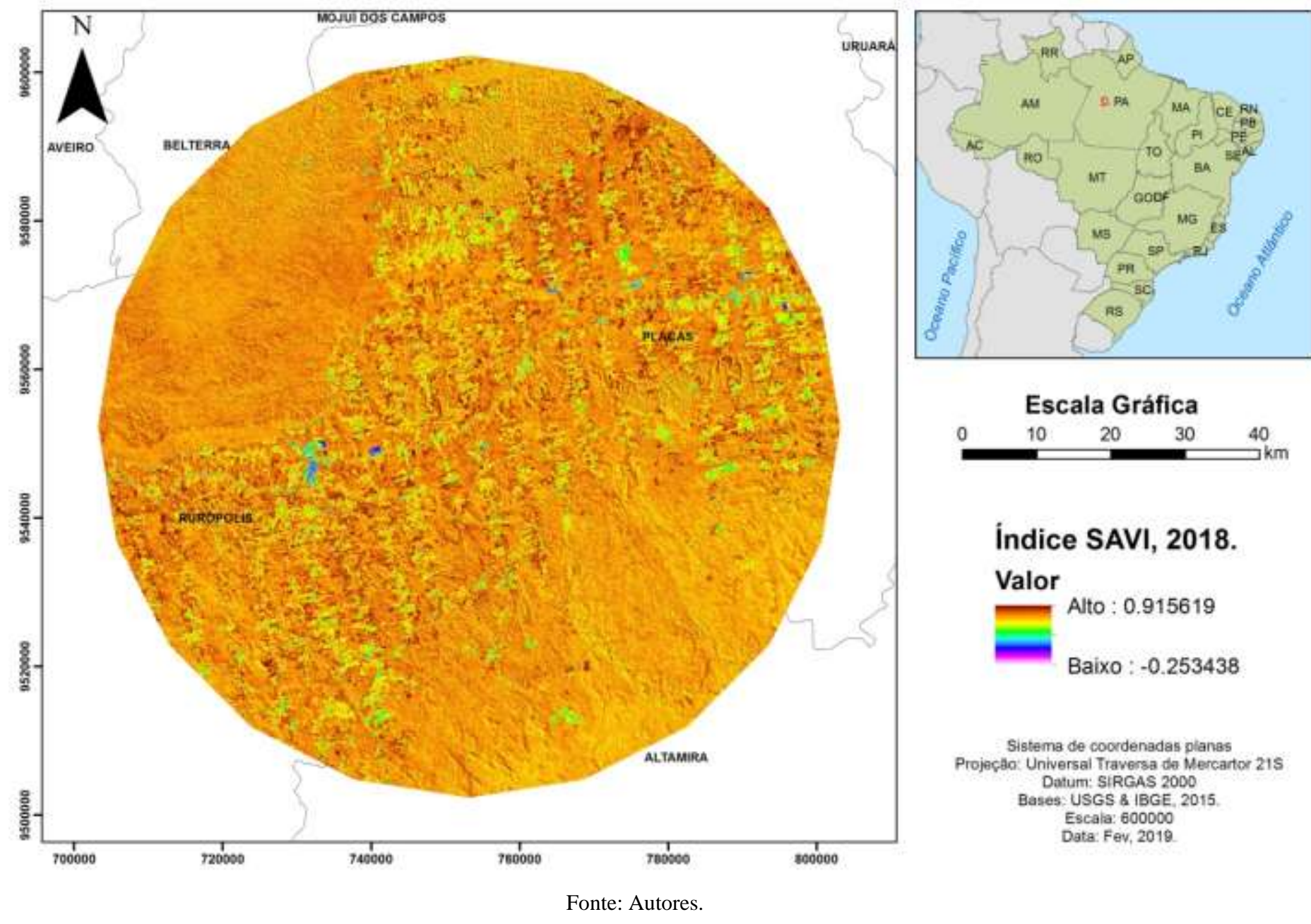

\subsection{Diferenças NDVI e SAVI}

A diferença entre os produtos do NDVI (2008 e 2018) e SAVI (2008 e 2018) são considerados iguais em termos numéricos. Por conta dos resultados se complementam e trabalham juntos para o melhor entendimento da área. Cada método atuando na sua devida finalidade, o método NDVI para destacar a vegetação, exemplificando a área da Flona Tapajós, a noroeste do mapa, com alto índice de reflexão, aproximadamente 1, como visto na Figura 7. O método SAVI responsável pela classificação de solo e vegetação torna melhor a observação da área (Figura 8), por isso, este índice é rotineiramente utilizado para analise do uso e ocupação do Solo, como exposto por Lima et al. (2017). 
Figura 7: Produto da diferença NDVI da comunidade analisada para o ano de 2008 e 2018.

Diferença NDVI da comunidade Linha Gaúcha - PA, 2008 e 2018.
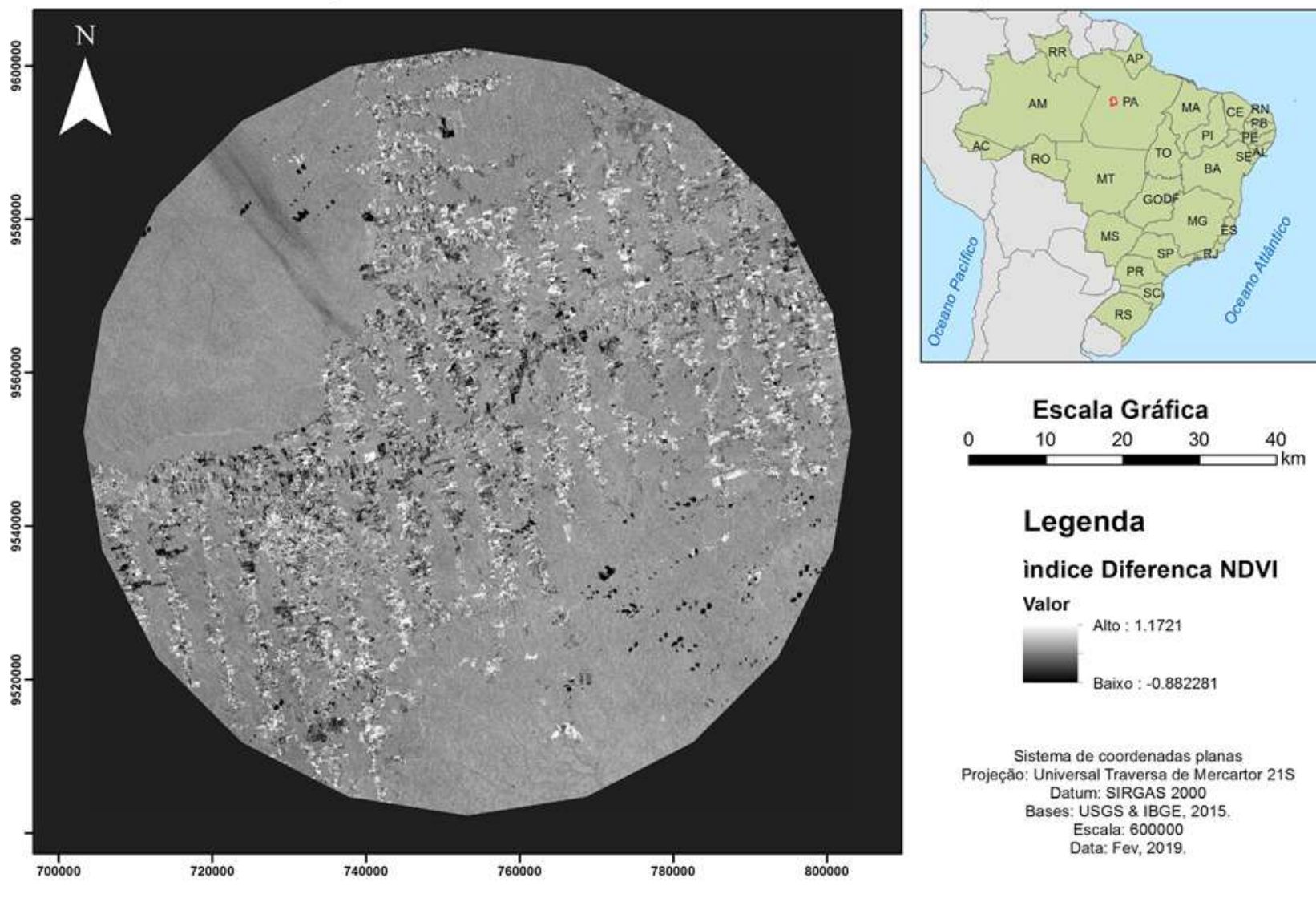

\section{Legenda}

indice Diferenca NDVI

Valor

Alto : 1.1721

Baixo : -0.882281

Sistema de coordenadas planas

Projeçăo: Universal Traversa de Mercartor 21S

Datum: SIRGAS 2000

Bases: USGS \& IBGE, 2015

Escala: 600000
Data: Fev, 2019

Fonte: Autores. 
Figura 8: Produto da diferença NDVI da comunidade analisada para o ano de 2008 e 2018.

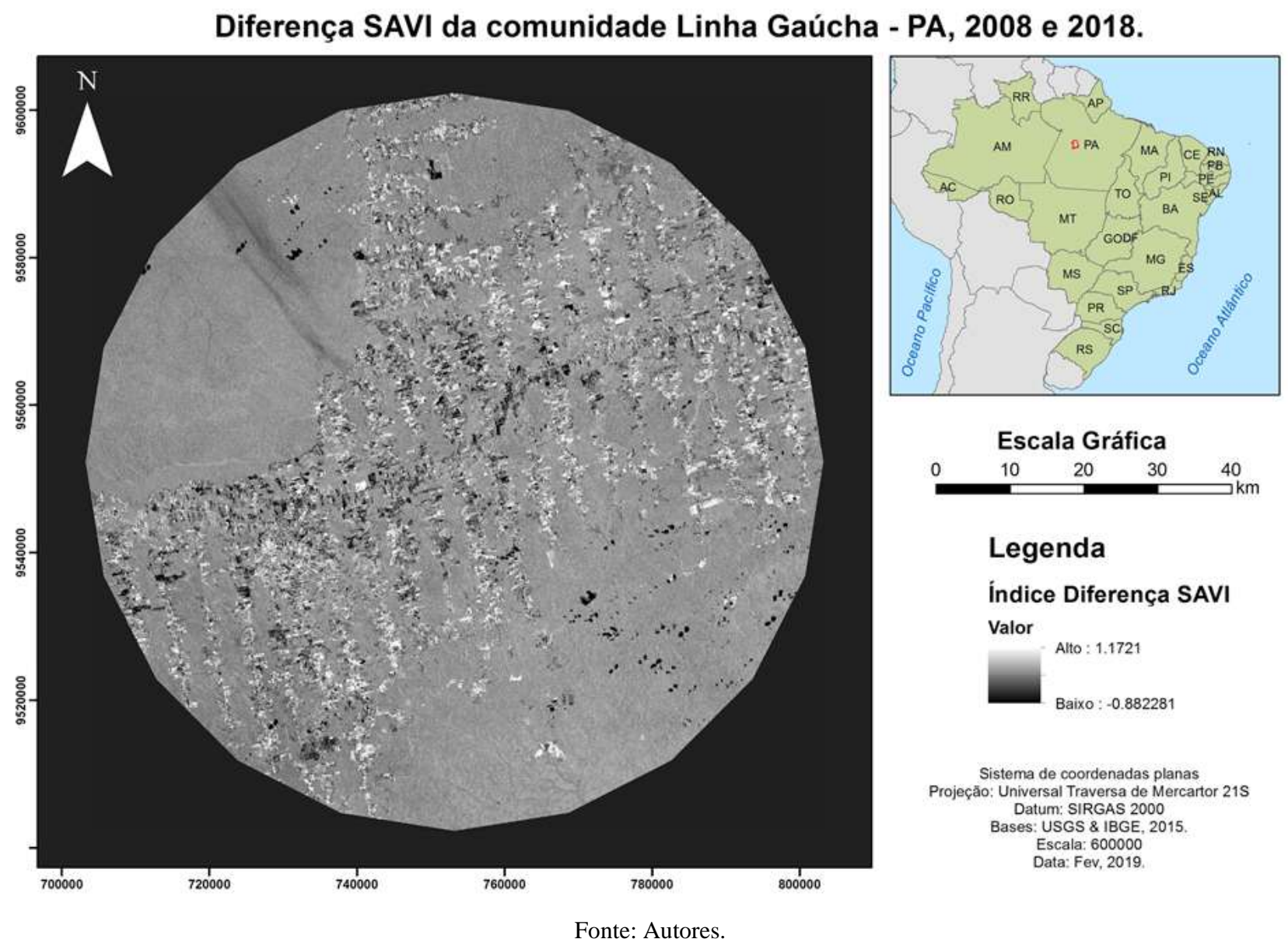

\section{Conclusão}

Com isso, pode-se dizer que o trabalho foi concluído com êxito, possibilitando a analise da expansão urbana em torno da comunidade de Linha Gaúcha (raio de $50 \mathrm{~km}$ ), no Pará, por meio do método de NDVI e SAVI. Na comunidade, pode-se observar uma intensa modificação no uso e ocupação do solo, este fato está intimamente ligado à presença da rodovia Transamazônica, importante agente de crescimento da Amazônia.

A presença da rodovia Transamazônica é um importante agente econômico, no entanto, também contribui para exacerbar a degradação ambiental da área de influencia. Na comunidade Linha Gaúcha é visível à supressão vegetal (2008 para 2018) por conta do crescimento urbano, que muita das vezes ocorre sem o devido planejamento ambiental.

Na área, tem-se o destaque para a Flona Tapajós, que no período de 10 anos (2008 a 2018), atua como um importante agente ambiental na conservação dos recursos naturais, por possibilitar a extração consciente na área, mas sem apresentar grandes impactos ambientais, contribuindo para a proteção de espécies ameaças.

\section{Referências}

Accioly. L. J. De O., Costa T. C. C., Oliveira M. A. J., Silva, F. H. B. B., \& Burgos, N. (2002). O papel do sensoriamento remoto na avaliação e no monitoramento dos processos de desertificação do semi-árido brasileiro. I Simpósio Regional De Geoprocessamento E Sensoriamento Remoto. 10.Anais... Aracaju/SE, 2002. p. 1-4.

De Boratto, I. M., \& Gomide, R. L. (2013). Aplicação dos índices de vegetação NDVI, SAVI e IAF na caracterização da cobertura vegetativa da região Norte de Minas Gerais. In: Embrapa Milho e Sorgo-Artigo em anais de congresso (ALICE). In: Simpósio Brasileiro De Sensoriamento Remoto, 16. 2013, Foz do Iguaçu. Anais... INPE, 2013. 7345-7352. 
Research, Society and Development, v. 11, n. 1, e47611122583, 2022

(CC BY 4.0) | ISSN 2525-3409 | DOI: http://dx.doi.org/10.33448/rsd-v11i1.22583

Empresa Brasileira De Pesquisa Agropecuária - Embrapa. (2019). LANDSAT - Land Remote Sensing Satellite. https://www.cnpm.embrapa.br/projetos/sat/conteudo/missao_landsat.html.

Florenzano, T. G. (2007). Iniciação em Sensoriamento Remoto. (3a ed.).

Gilabert, M. A. González-Piqueras. J. García-Haro, F. J. \& Melia, J. (2002). A generalized soil-adjusted vegetation índex. Remote Sensing of Environment. 82, 303-310.

Holben, B. N. (1986). Characteristics of maximum-value composite imagens from temporal AVHRR data. International Journal of Remote Sensing 7(11), $1417-1434$

Huete, Alfredo R. A. (1988). Soil-adjusted vegetation index (SAVI). Remote sensing of environment, 25(3), 295-309.

Introdução Ao Sensoriamento Remoto. 2001. http://docplayer.com.br/2709750-Introducao-ao-sensoriamento-remoto.html.

Jensen, J. R. (1996). Introductory digital image processing: a remote sensing perspective. (2a. ed.), Upper Saddle River: Prentice-Hall.

Lima, D. R. M. et al. (2017.). Uso de NDVI e SAVI para Caracterização da Cobertura da Terra e Análise Temporal em Imagens RapidEye. Revista Espacios, 38(36), $1-15 \mathrm{pp}$.

Masplam. (2019). Uso do Sensoriamento Remoto Auxilia na Preservação Ambiental. http://www.masplam.com.br/noticia/31/usos-do-sensoriamento-remotoauxilia-na-preservacao-ambiental.

Melo, E. T., Sales, M. C. L., \& De Oliveira, J. G. B. (2011). Aplicação do Índice de Vegetação por Diferença Normalizada (NDVI) para análise da degradação ambiental da microbacia hidrográfica do Riacho dos Cavalos, Crateús-CE. Raega-O Espaço Geográfico em Análise, v. 23.

Moraes, E. C. (2002). Capítulo 1: Fundamentos de Sensoriamento Remoto.

Novo, E. M. L. M. (1989). Sensoriamento remoto: princípios e aplicações. Edgard Blücher. 308 p.

Oliveira, L. M. T. V. (2008). Estudo das Regiões Fitoecológicas brasileiras pela FAPAR/NDVI e relações com séries temporais de dados pluviométricos. 226 p. Tese doutorado em Engenharia Civil - Universidade Federal do Rio de Janeiro.

Pettorelli, N. et al. Using the satellite-derived NDVI to assess ecological responses to environmental change. Trends in ecology \& evolution, 20(9), 503-510, 2005.

Rosendo, J. S. \& Sendo, J. S. (2005). Índices de vegetação e monitoramento do uso do solo e cobertura vegetal na Bacia do Rio Araguari - MG - utilizando dados do sensor MODIS. Dissertação de mestrado - Universidade Federal de Uberlândia, programa de Pós Graduação em Geografia. $\begin{array}{lllllllll}\text { Sausen, } & \text { T. } & \text { M. } & \text { (2019). } & \text { Sensoriamento } \\ \text { http://www3.inpe.br/unidades/cep/atividadescep/educasere/apostila.htm. }\end{array}$

Teotia, H. S., Silva, I. F., Santos, J. R., Veloso Junior, J. F., \& Gonçalves, J. L. G. (2003). Classificação da cobertura vegetal e capacidade de uso da terra na região do Cariri Velho (Paraíba), através de sensoriamento remoto e geoprocessamento. Anais XI Simpósio Brasileiro de Sensoriamento Remoto, Belo Horizonte, Brasil, 05-10 abril, INPE, $1969-1976$.

United States Geological Survey -Usgs. (2019). Base de dados Raster. 